\title{
Restructuring Law Enforcement Agencies to Support Prosocial Values: A Behavior Scientific \\ Model for Addressing Police Brutality
}

\author{
Elizabeth L. Ghezzi \\ Janie A. Funk \\ Ramona A. Houmanfar
}

${ }^{1}$ Elizabeth L. Ghezzi, Behavior Analysis Program, Department of Psychology, University of Nevada, Reno, 1664 N. Virginia St., Reno, NV 89557, USA, Elizabeth.ghezzi@nevada.unr.edu, 775-813-2597

${ }^{2}$ Janie A. Funk, Behavior Analysis Program, Department of Psychology, University of Nevada, Reno, 1664 N.

Virginia St., Reno, NV 89557, USA, funk.janie@gmail.com, 775-685-3554

${ }^{3}$ Ramona A. Houmanfar, Behavior Analysis Program, Department of Psychology, University of Nevada, Reno, 1664 N. Virginia St., Reno, NV 89557, USA, ramonah@unr.edu, 775-682-8693

We thank Courtney Smith for her contributions to earlier versions of this manuscript. 


\begin{abstract}
Policing in the United States is irrefutably a component of systemic racism. The history of police brutality against the Black community can be found in our amendments, laws, and cultural practices - it is an infrastructure of oppression. Though police brutality is not a new development, it has reached a fever pitch with the deaths of George Floyd and Breonna Taylor. Recent calls to defund the police puts law enforcement agencies squarely, and rightly, in the spotlight of social justice movements and reform. Current issues operating within law enforcement agencies ensure the perpetuation of a system that reinforces the status quo and gives nothing back to the communities that have been victims of brutality. A philosophical restructuring of how law enforcement agencies interact with the communities they serve is paramount. The purpose of this paper is to propose a behavior scientific model aimed at both the individual and organizational levels of law enforcement agencies using elements of Acceptance and Commitment Training (ACT) and Elinor Ostrom's core design principles (CDPs), called Prosocial. The Prosocial model promotes clarification of values within organizations and the communities they serve and reinforces valuesconsistent action. The model therefore has the potential to be a useful tool to combat systemic racism and police brutality within law enforcement agencies. The proposed model will be discussed in the context of those who created it (white academicians), who will be implementing it (law enforcement), and ultimately who should benefit from it above and beyond police brutality and without psychological or financial cost (Black communities).
\end{abstract}

Keywords: Prosocial, ACT, CDP, law enforcement agencies, police brutality, systemic racism 
This manuscript is being published on an expedited basis, as part of a series of emergency publications designed to help practitioners of applied behavior analysis take immediate action to address police brutality and systemic racism. The journal would like to especially thank Janani Vaidya and Alison Szarko for their insightful and expeditious reviews of this manuscript. The views and strategies suggested by the articles in this series do not represent the positions of the Association for Behavior Analysis, International or Springer Nature.

Guest Editor, Denisha Gingles 


\section{Restructuring Law Enforcement Agencies to Support Prosocial Values: A Behavior Scientific Model for Addressing Police Brutality}

Recent events, in particular the murders of George Floyd, Breonna Taylor, Ahmaud Arbery, and many others have brought attention to the centuries-long problem of systemic racism against the Black community. A critical preface to this paper is that we approach the discussion acknowledging the inherent racism being upheld within the United States, including but not limited to judicial and law enforcement, healthcare, and education. See Boutte and Bryan (2019), Henderson et al. (2019), and Dyer (2019) for in-depth discussions and examples. Law enforcement is the primary focus of this paper with the purpose of outlining a treatment model to help combat systemic racism and police brutality within law enforcement agencies. However, the remaining systems along with the components of law enforcement that this paper does not address, deserve our full attention and adequate resources.

In addition, our discussion about the effects of racism on Black communities are primarily with respect to Black men. It must be noted that Black men are not the only individuals who are harmed by the overt forms of racism that we discuss. Black women, children, transgender men and women, gender nonconforming, and members of the LGBTQ community all suffer at the hands of systemic racism. In fact, Marsha P. Johnson, a Black transgender woman, is credited as a major organizer and activist during the Stonewall social justice uprising in 1969 (Brown, 2019). Additionally, it is often overlooked that the founders of the leading global organization to eradicate white supremacy, \#BlackLivesMatter (BLM), are Black women (Patton \& Njoku, 2019).

Readers will notice that this paper includes discussion regarding the psychological experiences of law enforcement officers and the impact those experiences have on those being policed as it relates to the treatment model proposed. It is important to note that the stress police officers endure likely pales in comparison to the stress that Black, Indigenous and people of color (BIPOC) endure as a function of police hypervigilance, the generational trauma of BIPOC communities, compounded with other lived experiences of the perpetually oppressed (Akbar, 2017; Hackett, 2014). While it is beyond the scope of this paper, the injustices experienced by Black communities must not be discounted. See Rothstein (2017) for a more in-depth account of the disparities between Black and white communities as it relates to federal, state, and local laws that have been, and continue to be, intentionally designed to be discriminatory against African American people. The model proposed will therefore be discussed in the context of those who created it (white academicians), who will be implementing it (law enforcement), and ultimately who 
should benefit from it above and beyond police brutality and without psychological or financial cost (BIPOC communities).

Police brutality against African American people and communities is unfortunately not a new phenomenon, despite the recent surge of protests and demands for social justice in the United States (Alang et al., 2017). Systemic racism and its link to policing can be traced back to the South and the abolition of slavery. Slavery, as traditionally considered, was abolished in 1865, yet was and still is upheld in various guises. For instance, the convict lease system was a new way to exploit Black people. Targeting and arresting mainly Black men for petty crimes (i.e. loitering) ensured prisons were at capacity so that prisoners could be put to work for prison profit and private companies as another form of bound labor (Bauer, 2019). Moreover, reports at the time (late 1800s, early 1900s) used the terms "convicts" and "negroes" interchangeably (Forde \& Bowman, 2017). The history of policing in the United States is long, complex, and tied to economics and power rather than crime and crime control. For an indepth account, see Potter (2013) in which he succinctly sums up policing as follows, "Early American police departments shared two primary characteristics: they were notoriously corrupt and flagrantly brutal” (para. 4). Now, over 150 years later, policing tactics still predominantly target Black men. African American men are more than two times more likely than white men to be killed by police officers (Edwards et al., 2019). The history of systemic racism in law enforcement, social systems, and a myriad of other participatory factors (i.e. state and federal criminal laws, police unions, housing discrimination, etc.) ensures the perpetuation of a racist policing system. It is outside the scope of this paper to address each individual system that perpetuates police brutality as a function of systemic racism and the reality that each system is inextricably intertwined with the other. However, we can focus on two variables that likely moderate systemic racism within police departments: the psychological stress of the police officer that is characteristic of the profession, and more broadly, the social environment within law enforcement agencies.

\section{Law Enforcement Issues}

Jobs within the field of protective services are ranked the sixth highest occupations for suicide and have the highest overall female suicide rates when compared to other occupations (McIntoch et al., 2012). Sources of stress include the danger and risk inherent of the job, police administration issues, and lack of organizational support. In fact, it has been reported that between $12-35 \%$ of police officers suffer from post-traumatic stress disorder (PTSD), 
while others suffer from burnout and depression (Tucker, 2015). These stressors have implications personally, within the organization, and most importantly, on those who are policed.

The impact of police work on personal life include increased tension in relationships, higher rates of domestic abuse, substance abuse, divorce, and suicide (Finn et al., 2000; Scrivener \& Reese, 1994; Tucker, 2015). In addition, officers who have experienced a traumatic event on duty, and as a result suffer from PTSD, are more likely to become hypervigilant and/or hyperaroused (Violanti et al., 2017). Hypervigilance is defined as, "a panic-like state in which decision-making processes break down" (Junger, 2018, p. xv). When a police officer is hypervigilant they may approach a situation with panic and make a hasty and deadly decision (Janis \& Mann, 1976). Historically, these hasty and deadly decisions have disproportionately targeted the Black community and specifically Black boys and men (Edwards et al., 2019).

Compounding and participating in these problems are the widely underreported and undocumented rates of police misconduct. The Justice Department investigates less than .02\% of the country's 18,000 state and local lawenforcement agencies each year (Rushin, 2014). According to the Henry A. Wallace Crime Database, the top charges for police officers include aggravated assault, DUI, official misconduct/violation of oath, drug violations, and forcible fondling. A recent analysis of police misconduct in the United States puts the number of investigated and/or disciplined police officer incidents over the last decade at 85,000 (Kelly \& Nichols, 2020). In their reporting, Kelly et al. (2020) found that the top charges for police officers were excessive use of force, sexual misconduct, and domestic violence. Related to these charges is the issue of dishonesty. Kelly et al. cite over 2,000 records of perjury, tampering with evidence, tampering with witnesses, and falsifying reports. Researchers have argued that the source of police misconduct often comes from the occupation citing that police officers, "operate within a context of low supervision, low public visibility, and face-to-face encounters in which officers enjoy considerable power and authority over vulnerable citizens" (Stinson, et al., 2016, p.193). Additionally, there is no official nationwide database that collects, maintains, or disseminates data on police misconduct, police arrests, and police convictions (Stinson, et al., 2016). This issue is in large part because the federal government would have to collect data on arrests and convictions that rely heavily on self-report by law enforcement agencies (Owen \& McKinley, 2017). Put simply, law enforcement agencies have a history of protecting their officers rather than protecting the justice system and communities they serve in a consequence-free environment. It is clear that to address police brutality within law enforcement agencies it is necessary to target individual police officers and the system as a whole. 
When designing and planning for any intervention, it is critical to consider potential barriers.

Unfortunately, interventions to address psychological wellness remain underused by police officers for reasons that include confidentiality, stigma, and lack of confidence in the services delivered (Tucker, 2015). There is also an overall lack of empirical research investigating the effects of interventions on the wellness of law enforcement (Tanigoshi et al., 2008). Additionally, Patterson, et al. (2008) conducted a meta-analysis of stress management interventions with police officers and found that interventions were not effective; and a moderator analyses showed no meaningful differences across studies. One area that has been gaining popularity within law enforcement agencies to target police brutality at the individual level is implicit bias training. Implicit bias training, however, has been shown to not have lasting effects. A meta-analysis of 492 studies showed that implicit bias training did not alter people's behavior or as the authors state, "our findings suggest that changes in implicit measures are possible, but those changes do not necessarily translate into changes in explicit measures of behavior" (Forscher et al., 2019, p. 522). For example, a Chicago police officer sued the city after going through implicit bias training and subsequently shooting and killing an African American grandmother on accident (Weichselbaum \& Lewis, 2020). Blumberg et al. (2019) have suggested the use of police academy training packages to prepare police officers to respond to situations appropriately when on duty. Training packages vary in their immediate objectives. However, they all share the same ultimate goal of producing a more "high quality training" (Presidential Task Force on 21st Century Policing, 2015, p.53). Although what that high-quality training looks like at the state and local level can vary significantly (O’Neill et al., 2019). Behavior scientists have some experience in police academy training packages. O’Neill et al. (2019) focused police academy training on fluency of skills trained (i.e. defensive and control tactics), when to employ those tactics, and feedback; with the ultimate goal to avoid unnecessary force. These training packages are grounded in behavioral science, which lends to better measurement and more effective learning outcomes. However, they do not address current organizational and individual problems within law enforcement as they relate to systemic racism. Thus, a next step is an intervention rooted in behavioral science that also addresses existing systemic problems within law enforcement agencies.

\section{Intervention at the Individual Level: Acceptance and Commitment Training}

Acceptance and Commitment Training (ACT) aims to reduce human suffering and experiential avoidance by increasing psychological flexibility (Harris \& Hayes, 2009). Psychological flexibility as a construct is described as, "the ability to contact the present moment more fully as a conscious human being" (Hayes \& Strosahl, 2005, 
p.17). The ACT intervention model includes six core processes to promote psychological flexibility and they include, "acceptance, cognitive defusion, being present, self as context, values, and committed action" (Hayes, et al., 2012). Experiential avoidance and psychological flexibility are measured using the Acceptance and Action Questionnaire (AAQ-II; Bond et al., 2011; Hayes, et al., 2012), which has been efficacious in predicting various psychopathologies (Hayes et al., 2006). The impact of ACT on the improvement of well-being at the individual level has been empirically shown across many psychopathologies (A-Tjak et al., 2015). Moreover, acceptance and commitment training, not therapy, may be a less stigmatizing approach for a population with a potential bias against psychological wellness or "therapy" interventions. Behavior scientists have called for the use of ACT interventions within law enforcement (Mattaini \& Rehfeldt, 2020) and some behavioral health interventions that include ACT are currently being used with law enforcement professionals with promising results (Gallo, 2020). The Blue Life Academy is a behavioral health online resource for law enforcement professionals that focuses on the ACT core processes to increase psychological wellness by lowering stress, improving performance during challenging situations, and reducing emotional reactivity. Outside of behavior analysis, researchers have looked at the relationship between the issues listed above (e.g. PTSD, hypervigilance, depression) among police officers and "mindfulness" packages. A meta-analysis of these studies revealed that oftentimes the mindfulness measure was poorly defined and/or inconsistent (Grossman, et al., 2004). Further, these studies do not include an intervention but rather an analysis of the association between the level of severity of PTSD and mindfulness (Chopke \& Schwartz, 2013; Vujanovic, et al., 2009).

\section{Intervention at the Group Level: Prosocial}

Prosocial is a project created by The Evolution Institute (EI) with the goal to increase the efficacy of groups based on Elinor Ostrom's (1990) core design principles (CDPs). Ostrom studied the behaviors of successful common-pool resource groups and identified eight CDPs that characterized these groups. See table 1 for an outline and explanation of the eight CDPs.

The CDPs follow evolution theory in the context of cooperation, and humans as a cooperative species; which provides for a theoretical framework. Recent research in the area of cooperation has shown that some people will behave cooperatively even in the presence of a competing contingency to act "selfishly" (Rafacz et al., 2019, Ghezzi et al., 2020). Ghezzi et al. (2020) found that when people were identified as having a stronger history of reinforcement with cooperative stimuli compared to others, as predicted by the Implicit Relational Assessment 
Procedure (IRAP), the more likely they were to cooperate at higher and more sustained rates, while concurrently under a competing financial contingency to respond "selfishly." Alternatively, those with a weaker history of reinforcement with cooperative stimuli were less likely to cooperate and more likely to behave with respect to direct, individual contingencies, or act "selfishly." These studies are examples of systematic measurement approaches to identifying individual, implicit values and predicting how they may play out in explicit situations. Police officers that are identified as more "cooperative" may be more likely to adopt the CDPs and make values-based decisions in conflict management situations. Thus, when a group is working towards a common objective (i.e. promoting the principles of non-violent policing and eliminating systemic racism within law enforcement) rather than for direct, immediate individual contingencies, the CDPs are a useful framework for the group's success (Wilson et al., 2013). It is clear that the social environment within law enforcement agencies is lacking in CDPs (see table 1). To name a few: power imbalances (CDP2), absence of monitoring (CDP4), absence of punitive consequences (CD5), and biased conflict resolution (CD6). Given these problems, interventions that target individual police officers will be inadequate. To confront these systemic issues, Prosocial focuses on groups and multi-group social environments with three objectives:

1. Help individuals clarify why they care about their group and what gets in the way of effective collaboration;

2. Help groups learn about and adopt the CDPs to improve the efficacy in a practical sense; and

3. Create a scientific database for future improving knowledge about group efficacy. Prosocial training takes place through an online platform and in-person meetings. A trained Prosocial facilitator guides members through the training course as a group. Training introduces the group to the CDPs and prompts members to evaluate their group in the context of the CDPs. In addition, the second major component of Prosocial is a degree of ACT to facilitate greater psychological flexibility. Prosocial focuses on the ACT processes of perspective taking and committed action. Specifically, the Matrix is used to assist in the identification of thoughts and emotions, as well as actions and behaviors, that are consistent (or not) with stated values of the group. See Libman (2020) for a visual depiction of the Matrix that is used to work through CDPs noted as lacking. In doing this, individuals can clarify their own values as they relate to the organization's stated values and work toward committed action with respect to organizational values. 
The Law Enforcement Code of Ethics, outlined by the International Association of Chiefs of Police, was adopted in 1957. The Code of Ethics can be seen as several values statements that direct law enforcement agencies to committed action. Statements include protecting the innocent against deception, protecting citizens from oppression or intimidation, avoiding personal prejudices from compromising decisions, enforcing law courteously, and never employing unnecessary force or violence ("Law Enforcement Code of Ethics.” n.d.). It is plain to see that The Law Enforcement Code of Ethics are being violated and are contradictory to current policing practices (see sections above). An important part of implementing a Prosocial package with law enforcement in order to reduce racial bias is to clarify values that are not only consistent within the organization but the communities they serve and the relevant committed action to uphold these values. To do this, recognizing the infrastructure of oppression that has historically benefited white people is paramount. Prosocial, the CDPs, and ACT, all created by white academicians, may compromise parts of the BIPOC experience if not adapted (however ACT has been shown to be effective with clients from marginalized backgrounds, see Fuchs et al., 2013). Acknowledging this limitation, a Prosocial law enforcement model needs to recognize the history of over-policing BIPOC communities that has led to higher rates of police violence and overrepresentation in prison as compared to white communities. Additionally, an understanding of the history of systemic racism against African American people outside of law enforcement is also necessary. Thus, a Prosocial law enforcement agency model must include an educative component. As such, clarifying the values that align with the law enforcement agency and the communities they serve and reinforcing values-consistent action may help to combat systemic racism and police brutality. Moreover, secondary effects of employing the CDPs and psychological flexibility with Prosocial might lessen the stigma of officers receiving services, improve organizational support to seek out services, create an environment of accountability, establish better relationships between law enforcement and the community it serves, and reduce racial bias. What follows is an example of the application of a Prosocial training model in a law enforcement agency. The model is intended to promote non-violent policing practices with the ultimate goal to eliminate police brutality against BIPOC and improve the overall health of the communities that police officers serve.

\section{Prosocial Training Package}

In the event this proposed intervention were to be empirically evaluated, we will briefly discuss how this might be arranged to facilitate various relevant measures. The intervention could be implemented as a multiple baseline design across participants within the same agency. Following pre-treatment measures, participants could be 
randomly assigned to a treatment and waitlist group. Both groups would complete the Prosocial training as a group. Post-treatment measures would be taken for all participants following completion of Prosocial and on a weekly basis following for six weeks.

Individual measures of potential interest include the Dimensions of Anger Reactions Scale (DAR), Quality of Life Inventory (QOLI), Maslach Burnout Inventory - General Survey (MBI-GS), Acceptance and Action Questionnaire II (AAQ-II), the Prosocial Disposition Scale (PDS), and internal law enforcement agency records.

The DAR includes measures of psychological distress (including PTSD, depression, and anxiety), functional difficulties (relationships, daily activities, work problems, and substance use), and violence risk (Novaco, et al., 2012).

The QOLI measures well-being and life satisfaction across 16 domains (e.g., work, social). Scores provide a global measure of well-being and life satisfaction, as well as measures within the individual domains. This measure has been utilized to measure quality of life across many populations (Frisch, 2013).

The MBI-GS was developed to measure burnout in human service professionals. It has since been utilized to measure burnout across a variety of occupations, including law enforcement officers. Burnout is assessed across three subscales: exhaustion, cynicism, and professional efficacy (Bakker, et al., 2002). The AAQ-II consists of a seven-item scale to assess psychological flexibility (Hayes, et al., 2006).

To date, the Prosocial Disposition Scale (PDS) has been utilized to measure prosociality among urban adolescents (Drinkard, 2017). The proposed intervention serves as the first use of the measure in the law enforcement population and further validation and reliability research is warranted. However, the PDS serves as an acceptable measure of prosociality for this initial investigation of prosociality within the law enforcement community. The PDS is a self-administered assessment that measures prosociality on 56 items on a Likert scale. An example of one item assessed is "I try to be fair to others."

Internal records related to police misconduct could also be measured pre- and post- intervention, with a focus on reports involving BIPOC community members. Regardless of arranging the intervention in a way that facilitates an empirical evaluation, the measurement of how BIPOC and their communities are affected is nonnegotiable.

Recent calls by BLM and other activist groups to defund or re-allocate police funds need to be considered. A recent report using data from the federal Bureau of Economic Analysis found that the US spends twice as much 
on law and order as it does on cash welfare (Ingraham, 2020). However, it isn't as easy as slashing budgets. The larger question is how. Some have suggested reductions in budgets by suspending hiring, cutting overtime, and trimming personnel services (Stringer, 2020). Others have suggested police cost savings by reducing law enforcement fuel consumption (Shaenman \& Horvath, 2013). A push for re-imagining the role of police in communities by moving funds from law enforcement to community services is also growing in popularity. Many argue that the services police officers provide could be handled by other social service agencies. For example, emergency medical services, parking enforcement, traffic enforcement, mental health crises, and contracts with public schools and colleges all are handled by law enforcement (Weichselbaum \& Lewis, 2020). But, moving these responsibilities to social services also needs to include increased funding for those services. Employing a valuesbased package like Prosocial in community law enforcement agencies is ineffective if there are deficits in the community that those police officers serve. Funds that are re-allocated from law enforcement agencies to other services need to go directly to community services like housing development, job programs, education, health care, and legal services and must directly benefit Black communities.

\section{Discussion}

The issues outlined above concerning police officers and law enforcement agencies are detrimental and deadly to the Black communities they serve. Treatments to address these concerns have not always been implemented or even thoroughly carried out due to a variety of factors including confidentiality, stigma, lack of confidence in the delivered services, the culture within law enforcement agencies, and the overall complexity of the issue. The current training package may be a promising approach to address the psychological states of police officers and deep-rooted systemic issues within law enforcement agencies. Although the necessity of each component, ACT and the CDPs, have not been assessed, the utility of each intervention has been shown in related research. Acceptance and Commitment Training research has demonstrated its utility across a wide range of populations and behaviors; specifically, the utility of ACT has been demonstrated regarding depression and suicidal ideation in veterans (Cosio \& Schafer, 2015; Walser, et al., 2015) and law enforcement professionals (Gallo, 2020). In addition, the CDPs have been shown to be effective with an assortment of groups, one of which is neighborhoods. Wilson et al. (2013) discuss neighborhoods in which there is a lack of perceived cooperation and a sense from the people in the neighborhood that the individual must protect themselves. These concerns share similarities to those of 
law enforcement agencies and the communities they serve. Rather than having a cooperative and helpful attitude with community members, police officers often approach situations with an "us" versus "them" attitude.

Prosocial's effectiveness and ease of implementation allow it to be easily disseminated. Glasgow et al. (1999) propose what they term RE-AIM which is a framework for assessing an intervention's impact and its potential for dissemination. The framework is composed of five assessments: reach, efficacy, adoption, implementation, and maintenance. Previous research on the CDPs and ACT, as well as the outcome measurements of the proposed intervention, meet the five criteria outlined by Glasgow et al. (1999). The proposed package for law enforcement agencies offers flexibility of implementation and individuality towards addressing systemic racism and police brutality. Researchers considering the implementation of a Prosocial training package with law enforcement agencies may aid the agency and broader community they serve by contributing to an investigation manipulating components of Prosocial, such as emphasis on specific CDPs, varying exposure duration, or the level of interaction facilitated within the ACT exercises. Community outcome measures (e.g., police brutality, excessive force, etc.) may also lend to analyses regarding potential relationships with law enforcement psychological inflexibility, anger, aggression, burnout, and poor quality of life. As Embry and Biglan (2008) state, "Specifying fundamental units of behavioral influence could point to components to add to the existing programs and provide building blocks for creating new and more powerful programs" (p. 93).

However, to ensure support and consistent application of any Prosocial intervention, it is important for researchers to make contact and gain buy-in at the level of leadership within any law enforcement agency. The function of organizational leaders in our analysis of law enforcement practices is critical as they serve as the primary source for decision making and management of organizational practices. Establishing practices that support prosocial values and eliminate aversive conditions are more likely to be successful at the organizational level if they are first supported, communicated, and modeled by those in positions of leadership within that organization (Houmanfar et al., 2015). As discussed by Houmanfar et al. (2015), innovation in technologies such as social media and population level surveillance systems offers mechanisms to reliably estimate prosocial actions by law enforcement employees and tie these within contingency networks affecting leaders' actions. Resistance to this social intrusion on the daily practices of law enforcement officers will certainly occur but those at the leadership levels are in the position to promote social accountability via open systems of management and feedback. 
Funding programs like Prosocial may have to come from outside grant opportunities. A recent search on grants.gov of "police training" yielded 549 grant opportunities with many either being highly specific or international (Grants.gov, n.d.). Nonprofit groups, like The National Police Foundation, may be a more promising area for funding opportunities. Among other projects, The National Police Foundation funds program assessments and evaluations of local law enforcement agencies in order to recommend and implement training interventions and program designs ("What we do" n.d.). At the individual level, The National Institute for Health (NIH) may be an area for support. The NIH's Traumatic Stress Research Program funds studies related to mental health consequences of traumatic events and those more likely to experience posttraumatic pathologies. Relevant to the psychological issues related to police officers, one of the main goals of the program is to identify strategies to prevent chronic PTSD ("Traumatic Stress Research Program,” n.d.). The role of advocacy organizations (Alavosius et al., 2016; Biglan, 2009) is also critical as they provide a counterweight to the actions of organizational leaders and bring the perspective of communities affected by their practices and the potential for funding opportunities. The impact of many advocacy groups like BLM could benefit from lobbyists who can advance the public's interest in social justice movements as the lobbyists who advocate alternative views are often well organized and richly funded (Biglan, 2009). Government leaders (at federal, state, and local levels), under mounting pressure from social forces, may seek to direct their organizations' resources towards broader social values.

The call for serious, concrete plans to reform the judicial system and capitalism in general is not a novel idea. In 1982, Tony Platt's article calling for specific long-term and short-term policy reform, and the challenges we face in doing so, seems eerily similar to the context we find ourselves in now. "...It will be very difficult to achieve even the most modest successes and reforms because we are currently experiencing in the United States a concerted mobilization of conservative economic and political power" (p. 44). And while it looks like the current political tides are turning, Platt cautions readers to avoid being dogmatic in finding the "perfect" approach and argues for solutions that are flexible and context specific. With that in mind, a Prosocial model will not eradicate systemic racism within law enforcement agencies-- it is far from perfect. But, it is an attempt to start to restructure the philosophy of what policing looks like within law enforcement agencies and the communities it serves by clarifying core principles and values that are tied to prosocial leadership and organizational management (Houmanfar et al., 2015). After all, it is not in academic circles that solutions are found, rather it is in the implementation of interventions. 
As discussed in this paper, behavior analysis informs pragmatic solutions that can offer government and law enforcement leaders a promising strategy for cultural change. This is an area that can be of focus for behavior analysts with interest in social justice and related topics in culture-behavior science.

\section{Compliance with Ethical Standards}

\section{Conflict of Interest}

On behalf of all authors, the corresponding author states that there are no conflicts of interest.

\section{Ethical Approval}

Not applicable. 


\section{References}

Akbar, Maysa. (2017). Urban trauma: A legacy of racism. Publish Your Purpose Press.

Alang, S., McAlpine, D., McCreedy, E., \& Hardeman, R. (2017). Police Brutality and Black Health: Setting the Agenda for Public Health Scholars. American Journal of Public Health, 107(5), 662-665. https://doi.org/10.2105/AJPH.2017.303691

Alavosius, M.P., Newsome, W.D., Houmanfar, R. \& Biglan, A. (2016). A Functional Contextualist Analysis of the Behavior and Organizational Practices Relevant to Climate Change. In Robert Zettle, Steven C. Hayes, Dermot Barnes-Holmes, Anthony Biglan (Eds). Handbook of Contextual Behavior Science. Hoboken, NJ: Wiley-Blackwell

A-Tjak, J. G., Davis, M. L., Morina, N., Powers, M. B., Smits, J. A., \& Emmelkamp, P. M. (2015). A meta-analysis of the efficacy of acceptance and commitment therapy for clinically relevant mental and physical health problems. Psychotherapy and Psychosomatics, 84(1), 30-36. https://doi.org/10.1159/000365764

Bakker, A. B., Demerouti, E., \& Schaufeli, W. B. (2002). Validation of the Maslach Burnout Inventory - General survey: An internet study. Anxiety, Stress and Coping, 15(3), 245-260. http://doi.org/10.1080/1061580021000020716

Bauer, S. (2019). American prison: A reporter's undercover journey into the business of punishment. New York: Penguin Press

Biglan, A. (2009). The role of advocacy organizations in reducing negative externalities. Journal of Organizational Behavior Management, 29, 215-230.

Blumberg D. M., Schlosser M. D., Papazoglou K., Creighton S., Kaye C. C. (2019) New Directions in Police Academy Training: A Call to Action. International Journal of Environmental Research and Public Health, 16(24). DOI: 10.3390/ijerph16244941.

Bond, F. W., Hayes, S. C., Baer, R. A., Carpenter, K. M., Guenole, N., Orcutt, H. K., Waltz, T., \& Zettle, R. D. (2011). Preliminary psychometric properties of the Acceptance and Action Questionnaire-II: a revised measure of psychological inflexibility and experiential avoidance. Behavior Therapy, 42(4), 676-688. https://doi.org/10.1016/j.beth.2011.03.007 
Boutte, G., \& Bryan, N. (2019). When will Black children be well? Interrupting anti-Black violence in early childhood classrooms and schools. Contemporary Issues in Early Childhood, https://doi.org/10.1177/1463949119890598

Brown, D. (2019). Marsha P. Johnson: Transgender hero of Stonewall riots finally gets her due. USA Today. https://www.usatoday.com/story/news/investigations/2019/03/27/black-history-marsha-johnson-andstonewall-riots/2353538002/

Chopke, B. A., Schwartz, R. C. (2013) The Relation Between Mindfulness and Posttraumatic Stress Symptoms Among Police Officers. Journal of Loss and Trauma, 18:1, 1-9, DOI: $10.1080 / 15325024.2012 .674442$

Cosio, D. \& Schafer, T. (2015). Implementing an acceptance and commitment therapy group protocol with veterans using VA's stepped care model of pain management. Journal of Behavior Modifications, 38, 984-997.

Crosby, A. E., \& Molock, S. D. (2006). Introduction: Suicidal Behaviors in the African American Community. Journal of Black Psychology, 32(3), 253-261. https://doi.org/10.1177/0095798406290552

Drinkard, A. M. (2017). Predicting prosociality among urban adolescents: Individual, family, and neighborhood influences. Youth and Society, 49(4), 528-547. http://doi.org/10.1177/0044118X14543266

Dyer, L., Hardeman, R., Vilda, D., Theall, K., \& Wallace, M. (2019). Mass incarceration and public health: The association between black jail incarceration and adverse birth outcomes among black women in Louisiana. BMC Pregnancy and Childbirth, 19(1), 1-10. https://doi.org/10.1186/s12884-019-2690-z

Edwards, F., Hedwig, L., \& Esposito, M. (2019). Risk of being killed by police use of force in the United States by age, race-ethnicity, and sex. Proceedings of the National Academy of Sciences of the United States of America, 116(34), 16793-16798, DOI: https://doi.org/10.1073/pnas.1821204116

Embry, D. D. \& Biglan, A. (2008). Evidence-based kernels: Fundamental units of behavioral change. Clinical Child Family Psychological Review, 11, 75-113.

Finn, P., Talucci, V., \& Wood, J. (2000). On-the-job-stress in policing: Reducing it and preventing it. National Institute of Justice Journal, 242, 18-24.

Forde, K. R., Bowman, B. (2017). Exploiting Black labor after the abolition of slavery. U.S. 
News. https://www.usnews.com/news/national-news/articles/2017-02-07/exploiting-Black-labor-after-theabolition-of-slavery

Forscher, P. S., Lai, C. K., Axt, J. R., Ebersole, C. R., Herman, M., Devine, P. G., \& Nosek, B.

A. (2019). A meta-analysis of procedures to change implicit measures. Journal of Personality and Social Psychology, 117(3), 522-559. https://doi-org.unr.idm.oclc.org/10.1037/pspa0000160

Fuchs, C., Lee, J. K., Roemer, L., \& Orsillo, S. M. (2013). Using mindfulness- and acceptance-based treatments with clients from nondominant cultural and/or marginalized backgrounds: clinical considerations, meta-analysis findings, and introduction to the special series. Cognitive and behavioral practice, 20(1), 1-12. https://doi.org/10.1016/j.cbpra.2011.12.004

Frisch, M. B. (2013). Evidence-based well-being/positive psychology assessment and intervention with quality of life therapy and coaching and the Quality of Life Inventory (QOLI). Social Indicators Research, 114(2), 193227. http://doi.org/10.1007/s11205-012-0140-7

Kelly, J. \& Nichols M. (2020). We found 85,000 cops who've been investigated for misconduct. Now you can read their records. USA Today. https://www.usatoday.com/in-depth/news/investigations/2019/04/24/usa-todayrevealing-misconduct-records-police-cops/3223984002/

Gadson S. L. (2006). The third world health status of black American males. Journal of the National Medical Association, 98(4), 488-491

Gallo, F. (2020). ACT for law enforcement. Retrieved from https://contextualscience.org/act_for_law_enforcement

Ghezzi, E. L., Houmanfar, R. A., \& Crosswell, L. (2020). The motivative augmental effects of verbal stimuli on cooperative and conformity responding under a financially competing contingency in an analog work task. The Psychological Record, https://doi-org.unr.idm.oclc.org/10.1007/s40732-020-00400-7

Glasgow, R. E., Vogt, T. M., \& Boles, S. M. (1999). Evaluating the public health impact of health promotion interventions: The RE-AIM framework. American Journal of Public Health, $89,1322-1327$.

Grossman, P., Niemann, L., Schmidt, S., \& Walach, H. (2004). Mindfulness-based stress reduction and health benefits: A meta-analysis. Journal of Psychosomatic Research, 57, 35-43. 
Hackett, J. R. (2014). Mental health in the African American community and the impact of historical trauma: Systematic barriers. Retrieved from Sophia, the St. Catherine University repository website: $\underline{\text { https://sophia.stkate.edu/msw papers/320 }}$

Harris, R., \& Hayes, S. C. (2009). ACT made simple: An easy-to-read primer on acceptance and commitment therapy. Oakland: New Harbinger Publications.

Hayes, S. C., Luoma, J., Bond, F., Masuda, A., \& Lillis, J. (2006). Acceptance and Commitment Therapy: Model, processes, and outcomes. Behaviour Research and Therapy, 44, 1-25.

Hayes, S. C. \& Strosahl, K. D. (2005). A practical guide to Acceptance and Commitment Therapy. New York: Springer-Verlag.

Hayes, S. C., Strosahl, K., \& Wilson, K. G. (2012). Acceptance and Commitment Therapy: The process and practice of mindful change (2nd edition). New York: Guilford Press.

Henderson, D. X., Walker, L., Barnes, R. R., Lunsford, A., Edwards, C., \& Clark, C. (2019). A framework for racerelated trauma in the public education system and implications on health for Black youth. Journal of School Health, 89(11), 926-933. https://doi.org/10.1111/josh.12832

Houmanfar, R. A., Alavosius, M. P., Morford, Z. H., Herbst, S. A., \& Reimer, D. (2015). Functions of organizational leaders in cultural change: Financial and social well-being. Journal of Organizational Behavior Management, 35(1-2), 4-27. https://doi.org/10.1080/01608061.2015.1035827

Ingraham, C. (2020, June). U.S. spends twice as much on law and order as it does on cash welfare, data show. The Washington Post. https://www.washingtonpost.com/business/2020/06/04/usspends-twice-much-law-order-it-does-social-welfare-data-show/

Irving J. L., \& Leon Mann, L. (1976). Coping with decisional conflict: An analysis of how stress affects decision-making suggests interventions to improve the process. American Scientist, 64(6) 657-667 http://www. jstor.org/stable/27847557.

Junger, P. M. (2018). Effects of hypervigilance on decision-making during critical incidents. Master's thesis, Naval Postgraduate School, http://hdl.handle. net/10945/60416.

Law Enforcement Code of Ethics. (n.d.). Retrieved from https://www.theiacp.org/resources/law-enforcement-code- 
of-ethics

Libman, S. (2020, May). Prosocially incorporating the CDPs into the matrix: Theoretical implications and practical applications: By Stuart Libman, MD. Retrieved from https://www.prosocial.world/blog/prosociallyincorporating-the-cdps-into-the-matrix-theoretical-im

Mattaini, M. A., Rehfeldt, R. A. (2020). Editorial: Rendezvous with truth and discovery. Behavior and Social Issues. https://doi.org/10.1007/s42822-020-00034-y

McIntosh W. L., Spies E., Stone D. M., Lokey C. N., Trudeau A. T., Bartholow B. (2012) Suicide rates by occupational group — 17 States, 2012. Morbidity and Mortality Weekly Report, 65:641-645. http://dx.doi.org/10.15585/mmwr.mm6525a1.

Novaco, R. W., Swanson, R. D., Gonzalez, O. I., Gahm, G. A., \& Reger, M. D. (2012). Anger and postcombat mental health: Validation of a brief anger measure with U.S. Soldiers postdeployed from Iraq and Afghanistan. Psychological Assessment, 24(3), 661-675. http://doi.org/10.1037/a0026636

O'Neill, J., O'Neill, D. A., Weed, K., Hartman, M. E., Spence, W., \& Lewinski, W. J. (2018). Police academy training, performance, and learning. Behavior Analysis in Practice, 12(2), 353-372. https://doi.org/10.1007/s40617-018-00317-2

Ostrom, E. (1990). Governing the commons: The evolution of institutions for collective action. Cambridge [England] ; New York: Cambridge University Press.

Owen, T. \& KcKinley, I. (2017, Sept.) When cops commit crimes. Retrieved from https://news.vice.com/en_us/article/595kv3/police-crime-database

Patterson, G. T., Chung, I. W., \& Swan, P. W. (2014). Stress management interventions for police officers and recruits: A meta-analysis. Journal of Experimental Criminology, 10(4), 487-513. doi:http://dx.doi.org.unr.idm.oclc.org/10.1007/s11292-014-9214-7

Patton. L. D., \& Njoku, N. R. (2019) Theorizing Black women's experiences with institution-sanctioned violence: a \#BlackLivesMatter imperative toward Black liberation on campus. International Journal of Qualitative Studies in Education, 32(9), 1162-1182, DOI: 10.1080/09518398.2019.1645908

Platt, A. (1982). Crime and punishment in the United States: Immediate and long-term reforms from a Marxist perspective. Crime and Social Justice, 18, 38-45 
Potter, G. (2013). The history of policing in the United States. Retrieved from

http://www.plsonline.eku.edu/insidelook/history-policing-united-states-part-2

Presidential Task Force on 21st Century Policing. (2015). Final report of the President's task force on 21st century

policing. Washington, DC: Office of Community Oriented Policing Services. Retrieved from https://ric-zaiinc.com/Publications/cops-p311-pub.pdf

Rafacz, S. D., Houmanfar, R. A., Smith, G. S., Levin, M. E. (2019) Assessing the effects of motivative augmentals, pay-for-performance, and implicit verbal responding on cooperation. The Psychological Record, 69, 49-66.

Rothstein, R. (2017). The color of law: A forgotten history of how our government segregated America. London: Liveright Publishing Corporation

Rushin, S. (2014). Federal enforcement of police reform. Fordham Law Review, 82(6), University of Illinois College of Law

Schaenman, P. \& Horvath, A. (2013). Opportunities for police cost savings without sacrificing service quality: Reducing fuel consumption. The Urban Institute. Retrieved from: https://www.urban.org/sites/default/files/publication/23541/412803-Opportunities-for-Police-Cost-SavingsWithout-Sacrificing-Service-Quality-Reducing-Fuel-Consumption.PDF

Scrivner, E., \& Reese, J. (1994). Law enforcement families: Issues and answers. National Criminal Justice Reference Services. Washington D.C. Retrieved from https://www.ncjrs.gov/pdffiles1/Digitization/168113NCJRS.pdf

Stinson, P. M, Liederbach, J., Lab, S. P, \& Brewer, S. L. (2016). Police integrity lost: A study of law enforcement officers arrested. Report for the US Department of Justice. Retrieved from: https://www.ncjrs.gov/pdffiles1/nij/grants/249850.pdf

Stringer, S. M. (2020, June). Letter to Mayor Bill DeBlasio: Reducing and redirecting the NYPD budget. Retrieved from https://comptroller.nyc.gov/wp-content/uploads/2020/06/6.4.20-Letter-to-Mayorde-Blasio.pdf?utm_source=Media-All\&utm_campaign=c1d71b4e4bEMAIL_CAMPAIGN_2017_05_31_COPY_01\&utm_medium=email\&utm_term=0_7cd514b03ec1d71b4e4b-141571729

Tanigoshi, H., Kontos, A. P., Remley Jr., T. R. (2008). The effectiveness of individual wellness 
counseling on the wellness of law enforcement officers. Journal of Counseling and Development. 86, 6474.

The Evolution Institute. (n.d.). Prosocial. Retrieved from https://evolution-institute.org/projects/prosocial/

The Henry A. Wallace Crime Database. (n.d.). Retrieved from https://policecrime.bgsu.edu/

Training and Technical Assistance. (n.d.) Retrieved from https://www.policefoundation.org/what-we-do/trainingtechnical-assistance/

Traumatic Stress Research Program. (n.d.). Retrieved from https://www.nimh.nih.gov/about/organization/dtr/traumatic-stress-research-and-dimensional-measurementand-intervention-program/index.shtml

Tucker, J.M. (2015) Police officer willingness to use stress intervention services: The role of perceived organizational support, confidentiality, and stigma. International Journal of Emergency Mental Health and Human Resilience, 17, 304-314.

Violanti, J. M., Fekedulegn, D., Hartley, T. A., Charles, L. E., Andrew, M. E., Ma, C. C., \& Burchfiel, C. M. (2016). Highly rated and most frequent stressors among police officers: gender differences. American Journal of Criminal Justice, 41(4), 645-662. http://doi.org/10.1007/s12103-0169342-x

Violanti, J. M., Charles, L. E., McCanlies, E., Hartley, T. A., Baughman, P., Andrew, M. E., Fekedulegn, D., Ma, C. C., Mnatsakanova, A., \& Burchfiel, C. M. (2017). Police stressors and health: a state-of-the-art review. Policing (Bradford, England), 40(4), 642-656. https://doi.org/10.1108/PIJPSM-062016-0097

Vujanovic, A. A., Youngworth, N. E., Johnson, K. A., \& Zvolensky, M. J. (2009). Mindfulness-based acceptance and posttraumatic stress symptoms among trauma-exposed adults without axis I psychopathology. Journal of Anxiety Disorders, 23, 297-303.

Walser, R., Garvert, D., Karlin, B., Trockel, M., Ryu, D., \& Taylor, C. (2015) Effectiveness of acceptance and commitment therapy in treating depression and suicidal ideation in veterans. Journal of Behavioral Research and Therapy, 74, 25-31.

Weichselbaum, S., \& Lewis, N. (2020, June). Support For Defunding The Police Department Is 
Growing. Here's Why It's Not A Silver Bullet. The Marshall Project.

https://www.themarshallproject.org/2020/06/09/support-for-defunding-the-police-department-is-growinghere-s-why-it-s-not-a-silver-bullet

Wilson, D. S., Ostrom, E., \& Cox, M. E. (2013). Generalizing the core design principles for the efficacy of groups. Journal of Economic Behavior \& Organization, 90, S21-S32.

http://dx.doi.org/10.1016/j.jebo.2012.12.010 


\section{Tables}

Table 1. Outline of Ostrom's (1990) CDPs and explanation (Wilson et al., 2013)

Core Design Principle (CDP) Explanation (Wilson et al., 2013)

1) Clearly defined boundaries

The identity of the group and the boundaries of the shared resource are clearly delineated.

2) Proportional equivalence between benefits and costs
Negotiate systems that reward members for their contributions. High status or other disproportionate benefits must be earned. Unfair inequality poisons collective efforts.

3) Collective choice arrangements

Be able to create at least some of the rules and make decisions by consensus. People hate being told what to do but will work hard for group goals that they have agreed upon

4) Monitoring

6) Fast and fair conflict resolution
7) Local autonomy

5) Graduated sanctions
Commons are inherently vulnerable to free-riding and exploitation. Low cost strategies to detect these problems by norm-abiding members of the group are needed.
Transgressions don't require heavy-handed punishment, at least initially. Often gossip or a gentle reminder is sufficient, but more severe forms of punishment must also be waiting in the wings for use when necessary.

It must be possible to resolve conflicts quickly and in ways that are perceived as fair by members of the group.

Groups must have the authority to conduct their own affairs. Externally imposed rules are unlikely to be adapted to local circumstances and violate principle 3 .

Every sphere of activity has an optimal scale. Large scale governance requires finding the optimal scale for each sphere of activity and appropriately coordinating the activities, 